\title{
Can Clinical Data Predict Progression to Dementia in Amnestic Mild Cognitive Impairment?
}

\author{
Lesley Fellows, Howard Bergman, Christina Wolfson, Howard Chertkow
}

\begin{abstract}
Background: To determine whether clinical data obtained by history and physical examination can predict eventual progression to dementia in a cohort of elderly people with mild cognitive impairment. Methods: A prospective, longitudinal study of a cohort of elderly subjects with amnestic Mild Cognitive Impairment (MCI). Ninety subjects meeting the criteria for amnestic MCI were recruited and followed annually for an average of 3.3 years. Main outcome measure was the development of dementia determined by clinical assessment with confirmatory neuropsychological evaluation. Results: Fifty patients (56\%) developed dementia on follow-up. They were older, had lower Mini-mental status exam (MMSE) scores and a shorter duration of symptoms at the time of first assessment. Multivariate logistic regression analysis identified age at symptom onset as the only clinical parameter which distinguished the group that deteriorated to dementia from the group that did not. The odds ratio for age was 1.1 (confidence interval 1.04 - 1.18). Conclusions: Patients presenting with amnestic MCI insufficient for the diagnosis of dementia are at high risk of developing dementia on follow-up. In our cohort, $56 \%$ were diagnosed with dementia over an average period of 5.9 years from symptom onset. The only clinical predictor for the eventual development of dementia was older age at symptom onset. Clinical features alone were insufficient to predict development of dementia.
\end{abstract}

RÉSUMÉ: Les données cliniques peuvent-elles prédire la progression vers la démence dans l'atteinte cognitive légère avec syndrome amnésique? Contexte : Le but de cette étude était de déterminer si les données cliniques provenant de l'histoire médicale et de l'examen physique peuvent prédire la progression éventuelle vers la démence dans une cohorte de gens âgés ayant une atteinte cognitive légère. Méthodes : Il s'agit d'une étude longitudinale prospective d'une cohorte de sujets âgés ayant une atteinte cognitive légère (ACL). Quatre-vingt- dix sujets rencontrant les critères diagnostiques de l'ACL amnésique ont été recrutés et suivis annuellement pendant 3,3 ans en moyenne. Le critère d'évaluation principal était l'apparition d'une démence selon l'évaluation clinique confirmée par une évaluation neuropsychologique. Résultats : Cinquante patients (56\%) ont développé une démence au cours du suivi. Ils étaient plus âgés, avaient des scores MMSE plus bas et un début des symptômes plus récent au moment de la première évaluation. Une analyse de régression logistique multivariée a identifié l'âge au moment du début des symptômes comme le seul paramètre clinique qui distinguait le groupe de patients qui évoluaient vers une démence du groupe de patients sans démence. Le rapport de cotes pour l'âge était 1,1 (IC 1,04 à 1,18). Conclusions : Les patients qui consultent pour une ACL amnésique dont le tableau clinique n'est pas suffisamment sévère pour qu'on pose un diagnostic de démence sont à haut risque de présenter une démence par la suite. On a posé un diagnostic de démence chez $56 \%$ des patients de cette cohorte, en moyenne 5,9 ans après le début des symptômes. La seule donnée qui prédisait l'apparition éventuelle de la démence était un âge plus avancé au début des symptômes. Les caractéristiques cliniques étaient insuffisantes pour prédire le développement de la démence.

Can. J. Neurol. Sci. 2008; 35:314-322

As treatments to alleviate symptoms and to slow the progression of Alzheimer's disease (AD) emerge, an increasingly urgent dilemma for physicians is also developing: which of the many elderly individuals with memory complaints will develop Alzheimer's disease, and would therefore be candidates for preventive therapies? An important goal of current research must be to establish useful pre-clinical diagnostic and predictive guidelines, and this can only emerge from longitudinal follow-up of elderly individuals with mild memory loss. In this paper, we report the clinical characteristics of such a group, with the aim of
From the Bloomfield Centre for Research in Aging (HC, HB), Division of Geriatric Medicine, Dept. of Medicine (HB, HC), Dept. of Neurology and Neurosurgery (LF, HC), Division of Clinical Epidemiology, McGill University Health Centre, Department of Epidemiology, Biostatistics \& Occupational Health, Department of Medicine, McGill University (CW); Research Centre, Institut Universitaire de Gériatrie de Montréal (HC), Montreal, Quebec, Canada.

Received August 10, 2006. Final Revisions Submitted January 7, 2008. Reprint requests to: Howard Chertkow, Bloomfield Centre for Research in Aging, Sir Mortimer B. Davis -Jewish General Hospital, McGill University, Montreal, Quebec, Canada, H3T 1E2 
determining which clinical characteristics might predict progression to Alzheimer's disease.

\section{The concept of Mild Cognitive Impairment}

Various terms have been developed to describe individuals with mild memory loss. ${ }^{1,2}$ Mild Cognitive Impairment (MCI) is now the most common term and we have used the criteria for MCI in characterizing our group of subjects. Mild Cognitive Impairment is a classification originally defined in the ICD- $10^{3}$ as subjective report of cognitive decline from a former level, gradual in onset, and present for at least six months. There is now consensus around a definition of MCI defined by a set of clinical symptoms- subjective memory complaints, objective evidence of memory loss, with other cognitive domains remaining "generally intact", no significant daily functional disability, and absence of a clinical diagnosis of dementia. ${ }^{4,5}$ The majority of MCI individuals seen in Memory Clinics are "amnestic" in that memory is the major cognitive domain affected. Winblad et al ${ }^{6}$ and others have more recently subclassified MCI into "amnestic MCI" (memory only impaired), "amnestic plus multiple domains MCI" (Memory plus Other, where "Other" is executive function, language, attention or visuospatial function), or Single Nonmemory domain (Other Only label). These subclassifications are usually on the basis of detailed neuropsychological evaluation, but at a clinical level, MCI showing primarily subjective and objective memory loss could be classified as "amnestic". Mild cognitive impairment excludes individuals with significant depression, delirium, mental retardation, or other psychiatric disorders likely responsible for the impairment.

Two alternative approaches have been used in delineating elderly subjects with mild memory loss, and these will be briefly discussed. One evaluation is according to the Clinical Dementia Rating (CDR) scale. In this scale, a very similar group is termed "Questionable Dementia". 7 Individuals so classified show mild consistent forgetfulness with partial recollection of events, with mild or no impairment in hobbies and community affairs. The rating of CDR 0.5 is assigned to such individuals. While cognitive "domains" of memory, orientation, judgment, social function, hobbies, and personal hygiene are all assessed, the algorithm for calculating the rating weights memory heavily. ${ }^{8}$ It has been noted, however, that although most MCI individuals score as CDR 0.5, there are some other CDR 0.5 individuals who would be better classified as already demented, with mild AD., ${ }^{9,10}$

Another term, Age-Associated Cognitive Decline applies to patients who report gradual cognitive decline over at least six months. ${ }^{11}$ Memory and learning can be affected (the usual pattern) as well as attention, abstraction, and language. Patients must show abnormal performance (at least 1 standard deviation (SD) below the norm for age-appropriate populations) on tests of cognitive function for which age and education norms are available.

\section{Natural history of Mild Cognitive Impairment}

It is clear now that Alzheimer Disease has its onset many years before clinical symptoms occur. ${ }^{12-14}$ As a corollary to this, MCI represents a state of increased risk for development of AD. ${ }^{15-18}$ Progression of MCI patients to dementia (mainly AD) occurs at an initial rate of about $15-30 \%$ per year in Memory
Clinic samples. ${ }^{17,19-22}$ Some individuals with MCI, however, remain only mildly impaired for many years, and may never progress to dementia. ${ }^{23}$ Visser et $\mathrm{al}^{24}$ reported that about half of the MCI subjects in a European Memory Clinic progressed to dementia over ten years follow-up. In our Montreal Memory Clinic cohort, about $75 \%$ of MCI subjects eventually go on to dementia, and $25 \%$ do not. ${ }^{25,26}$ Distinguishing which subjects will or will not progress is of obvious clinical importance, both in terms of prognosis and management.

\section{Clinical risk factors for development of dementia and AD}

There is currently a great deal of interest in defining clinical, neuropsychological, genetic, imaging, and biological features which identify those subjects with $\mathrm{MCI}$ who will progress to $\mathrm{AD}$, and those who will not. In this study, we evaluated whether information obtained on clinical examination allows this distinction to be drawn. Obviously, the most useful indicators would be those readily available to clinicians at the bedside or in the clinic itself, without need for more sophisticated work-up. We will not address the question (applicable only to specialty clinics) of whether neuropsychological ${ }^{27}$ or combined neuropsychological, imaging, and genetic algorithms ${ }^{28,29}$ might allow accurate prognostication in MCI cases.

The literature supplies evidence for a number of clinical features which might identify those patients who are at a preclinical or at least an early stage of AD. Risk factors for development of dementia in population studies of elderly normal subjects may be of prognostic value in patients with mild cognitive impairment. The risk factors that derive from the literature include age,,$^{29,30}$ a family history of dementia, ${ }^{31}$ history of head injury, ${ }^{32,33}$ depression, ${ }^{34,35}$ as well as low pre-morbid intelligence and education. ${ }^{36-38}$ Female gender has been noted to be a risk factor for dementia in a number of studies, ${ }^{30,39-41}$ although this has not been found in others. ${ }^{42-46}$

The onset of subjective memory complaints may be a risk factor for development of subsequent cognitive decline..$^{47-50}$ Other research teams have, in contrast, noted that subjective complaints alone do not predict decline in the absence of objective memory loss. ${ }^{16}$ Relatives' report of memory deterioration also appears to accurately detect mild cognitive impairment even in the absence of measurable neuropsychological deficits. ${ }^{8,51-53}$ It is not clear that new neuropsychological subtypings of MCI lead to any increase in predictive ability. ${ }^{54}$

There is growing evidence that signs and symptoms of vascular disease are important risks for dementia, and even for AD. The Rotterdam study stressed the important predictive value of diabetes mellitus, atrial fibrillation, blood pressure, and serum homocysteine levels in predicting occurrence of dementia in a general elderly population. ${ }^{55-59}$ Smoking was a risk factor for dementia in this as well as other studies of the general population. ${ }^{30,60}$

Physical examination may also supply prognostic information. Frontal release signs, impaired gait, and increased rigidity may occur more frequently early in the course of dementia. ${ }^{31,61-65}$ In a recent study, gait disturbance was often reported to the family doctor up to five years before dementia was diagnosed. ${ }^{65}$ 
While risk factors for $\mathrm{AD}$ in the general population are of interest, it is unclear whether they are relevant in predicting dementia in that subset of the population presenting to a Memory Clinic with mild cognitive impairment. Studies of such cohorts have identified several possible predictors: It has been suggested that the most highly predictive elements of the history are report by the family that the patient's memory has declined over the previous 12 months, and that the cognitive decline is having some impact on function. ${ }^{66-68}$ Finally, there are a growing set of reports using results of particular neuropsychological tests, biomarkers, and neuroimaging, in order to better predict which individuals with MCI will progress to AD. While these are beyond the scope of this article, they are addressed in a number of reviews. ${ }^{1,2,69}$

In summary, the available studies have focused on different aspects of the clinical and neuropsychological assessment, but to our knowledge, none have assessed the utility of information derived from the clinical assessment as a whole. It is not clear that, in a typical clinical setting, assessment of clinical risk factors in an MCI patient will help predict the chances of progression.

This study explores the hypothesis that the subset of patients with MCI destined to develop dementia can be distinguished from those with stable memory difficulties on clinical grounds alone. A rigorously defined cohort of patients with mild cognitive impairment was identified; this cohort met current criteria for MCI. ${ }^{5,70} \mathrm{We}$ report the results of the initial clinical evaluations and identify the factors which were associated with the development of dementia.

\section{SubJects And Methods}

\section{Subjects}

Subjects were recruited as a convenience sample from 215 consecutive individuals with MCI seen on a physician referral basis at the Jewish General Hospital (JGH)/McGill University Memory Clinic over a five year period. All had memory complaints, and they underwent clinical assessment as part of their initial work-up, with careful itemized documentation of all aspects of their clinical presentation.

Ninety subjects meeting the above criteria for MCI were recruited. All had presented to their family physician with complaints (from the individuals themselves or their families) of memory loss. All were assessed in the Memory Clinic by a neurologist or geriatrician skilled in assessment of memoryimpaired elderly individuals, and were judged as also able to meet the criteria for Mild Cognitive Impairment defined in the working group of Winblad et al, ${ }^{6}$ and the MCI Working Group of the European Consortium on Alzheimer's Disease, ${ }^{71}$ as well as Petersen in his original operational definition of MCI. ${ }^{72,73}$ All had a history of memory decline in the last one to four years reported by the patient, caregiver (usually the spouse), or both, of a sufficient degree to bring them to medical attention. The date of onset of memory difficulties was provided by spouse or caregiver. In the clinical judgment of the specialists assessing these individuals, there was "memory impairment beyond what was felt to be normal for age, but... [they] were relatively intact in other cognitive domains". ${ }^{74}$ All subjects received the same evaluation and were documented to have objective memory impairment on a standardized mental status exam, the JGH Memory Clinic Assessment (unpublished but available from the corresponding author), which contains elements of the CERAD, CDR, and Toronto Behavioural Neurology Assessment batteries appropriate for mild dementia subjects. ${ }^{75}$ Deficits in other cognitive areas (outside of short term memory) were judged as minimal and not sufficient to imply a clinical diagnosis of dementia. On informal assessment, subjects agreeing or not agreeing to participate in this study did not differ in any appreciable demographic features. All were deemed capable of giving informed consent.

All subjects met criteria for Amnestic MCI ${ }^{5}$ with or without other cognitive impairments, and they had an initial and major complaint of memory loss (almost all of the MCI individuals referred to the Memory Clinic had this complaint), supported by clinical evidence of objective impairment in memory beyond normal. The subjects did not meet the National Institute of Neurological and Communication Disorders Sciences Alzheimer's Disease and Related Disorders Association (NINCDS-ADRDA) criteria for the diagnosis of probable AD or dementia. That is, they did not have evidence of other cognitive deficits or impairment of daily functioning.$^{76}$ All were classified according to the Washington University CDR scale and met the criteria for " 0.5 " on that scale. ${ }^{7,77}$ All subjects also met criteria for Age-Associated Cognitive Decline. ${ }^{11}$ Full details of their characterization are presented elsewhere. ${ }^{78-80}$

A standardized clinical history was taken and recorded, recording presence of current or past smoking, diabetes, cancer, hypertension, etc., along with best estimates of alcohol consumption and smoking. The clinical variables were assessed and tabulated. Family history was defined liberally as even one member of the immediate family with a history of AD. Precipitants for AD were recorded liberally. Family members and subjects were asked "was there anything that seemed to trigger the memory loss", and then a list of possible triggers general anaesthetic, a severe stress, illness, etc. - were provided. The caregiver's assessment of the course (stable vs. progressing memory loss over the previous year) was also assessed.

Caregiver's assessment of the presence or absence of behavioural changes, emotional changes (anxiety, depression, apathy) or functional changes, were also tallied. Report of functional changes was assessed using the Pfeiffer Functional Activities Quotient. ${ }^{81}$

A standardized physical exam was carried out, looking specifically for lateralizing signs, extrapyramidal signs (rigidity, tremor, bradykinesia), frontal release signs, abnormal movements, gait impairment, increased tone and hyperreflexia, and impairment of eye movements. There was no evidence on clinical evaluation of systemic or other neurological disease sufficient to interfere with cognitive function. Structural brain disease was excluded by CT and/or MRI. Screening for underlying systemic illness included a CBC, routine chemistry, thyroid function, syphilis screen, and serum $B_{12}$ and folate. All subjects scored less than 4 on the Hachinski ischemic scale. ${ }^{82}$ The Mini-mental status exam (MMSE) ${ }^{83}$ was carried out by the clinician as a global assessment tool.

All subjects underwent a full neuropsychological evaluation, which will be reported separately. Major depression was excluded via a score less than 16 on the full (30 item) Yesavage 
Geriatric Depression Scale. ${ }^{84}$ Mild depression (score 6 to 16 ) was allowed. The diagnosis of MCI was supported by a neuropsychological evaluation establishing that a) there was memory performance at least 1.0 and usually 1.5 standard deviations below the mean for age and education on one of the RAVLT (Rey Auditory Verbal Learning Test), ${ }^{85}$ or the Logical Memory (paragraph recall) subtest of the Wechsler Memory Scale - Revised, ${ }^{86}$ and b) the DSM-III criteria for dementia were not met.

The subjects were then followed annually with both clinical assessment and repeat neuropsychological examination. All subjects were followed for at least one year. Those who developed dementia on follow-up (the Progressors) were compared to those who remained in the MCI category (the NonProgressors) in terms of the clinical data collected at the initial assessment. The clinical data were formally compiled by an investigator blinded to outcome.

\section{Statistical analysis}

As a first step, those who went on to develop dementia were compared to those who did not on demographic and clinical variables using chi-square and t-tests as appropriate. All clinical parameters that were found to be different between the two groups $(\mathrm{p}<0.1)$ were entered into a logistic regression model. Possible multicollinearity was assessed by considering pairwise correlations between variables.

A step-wise approach was used to determine which measures contributed to discriminating between patients who developed dementia and those who did not. Two models were created because some clinical information was missing for three of our subjects. One model excluded those subjects; the other included them by replacing the missing values with the mean of the group for these measures. The same measures contributed to discriminating between the two groups in both models. The results from all 90 subjects are therefore presented here.

\section{RESULTS}

At the time of initial evaluation, the 90 subjects had an average age of 73.7 years (range 58-84) and an average MMSE score of 27.5 (range 23-30). There were 45 men and 45 women, with an average of 10.7 years of education (range 4-22). The mean duration of reported memory loss prior to presentation was 2.6 years (SD 2.1), with the mean age at symptom onset 71.1 years (SD 8.2). Demographic variables are summarized in Table 1. All subjects scored at least 1.0 standard deviation (and usually 1.5 standard deviations) below the age-adjusted mean on one or more memory test administered.

Mean follow-up was 5.9 years (SD 2.7) from the time of symptom onset, or 3.3 years (SD 1.3) following the first clinic visit. Fifty subjects $(56 \%)$ deteriorated to the point of dementia (meeting DSM-III criteria for probable or possible AD in all cases), while 36 remained in the MCI category. Length of follow-up from symptom onset was similar in both groups (Table 2). Four were reassessed as "normal" on follow-up, and will be considered with the MCI "non-progressors" for statistical comparisons. Two subjects died just prior to their first annual follow-up. Information from family members and the subjects' primary care physicians indicated that they had not demonstrated cognitive deterioration to that point, and they are included with the MCI non-progressors category. Another two subjects died following one year of follow-up, at which time they were still classified as MCI. There were no other losses to follow-up. These four subjects were included in the MCI category in the analysis reported here. Any misclassification due to loss to follow-up is likely to attenuate the difference between the two groups. As such, our findings may under-estimate the predictive value of the clinical data studied.

Univariate analysis revealed significant differences between the group that developed dementia on follow-up (the progressors), and the group that remained classified as MCI (the non-progressors). The 'dementia' group was older at the time of symptom onset, and had a statistically significantly lower score

Table 1: Demographic and selected clinical information

\begin{tabular}{lccc}
\hline & total sample & MCI on follow-up & AD on follow-up \\
$\mathrm{n}$ & 90 & 40 & 50 \\
mean age of onset (SD) & $71.1(8.2)$ & $66.9(8.5)$ & $74.5(6.3)^{* *}$ \\
sex (\% female) & 50 & 42.5 & 56 \\
education (SD) & $10.7(3.5)$ & $10.9(3.3)$ & $10.6(3.6)$ \\
mean MMSE score at entry & $27.5(1.9)$ & $28.1(1.9)$ & $27.0(1.7)^{* *}$ \\
mean symptom duration at entry (SD), y & $2.6(2.1)$ & $3.2(2.2)$ & $2.1(2.0)^{*}$ \\
mean length of follow-up from symptom onset (SD), y & $5.9(2.7)$ & $6.3(2.9)$ & $5.6(2.5)$ \\
smoking history (\% ever smoked) & 50 & 52.5 & 48 \\
\hline
\end{tabular}

${ }^{*} \mathrm{p}<0.05,{ }^{*} \mathrm{p}<0.01$ comparing those remaining MCI and those progressing to AD. $\mathrm{n}=$ number, $\mathrm{y}=\mathrm{year}$ 
Table 2: Length of follow-up from symptom onset by final diagnosis

\begin{tabular}{|c|c|c|c|c|c|}
\hline Length of follow-up, $y$ & $1-3$ & 3.1-5 & 5.1-7 & 7.1-9 & $>9$ \\
\hline $\mathrm{MCI} /$ Non-progressors ( $\%$ of group) & 7.5 & 30 & 27.5 & 17.5 & 17.5 \\
\hline AD/Progressors ( $\%$ of group) & 10 & 38 & 32 & 10 & 10 \\
\hline
\end{tabular}

$\mathrm{y}=\mathrm{year}$

on MMSE at presentation. This group had also been symptomatic for a shorter period of time. There was a tendency for those in the MCI non-progressors group to report having smoked more than those in the dementia progressors group (16 \pm 24 vs. $8 \pm 12$ pack-years; $\mathrm{p}=0.08)$, although this did not reach statistical significance. Given the uncertainty inherent in retrospectively establishing a precise smoking history, the data were also analyzed in terms of 'ever' vs. 'never' smoked. There was no difference in this regard between the two groups.

No significant difference between the two groups was found for a variety of other clinical information. The broad categories assessed are listed in Table 3.

Based on the results of the univariate analysis, the following variables were entered into a logistic regression model: age at symptom onset, score on MMSE, any history of smoking, and symptom duration. Level of education, sex, and evidence of a change in functional status were also included in the model, as they have been found to be important in other studies. No pairwise correlations greater than 0.6 were found between variables, so all were included.

Logistic regression identified only older age at presentation as contributing significantly to discriminating between those who subsequently developed dementia, and those who remained in the MCI group. The odds ratio was 1.11 (CI 1.04-1.18) for each added year of age at presentation. A non-statistically significant trend was seen for both initial MMSE score, and smoking history. These results are summarized in Table 4.

Table 3: Clinical data not statistically significantly different in the MCI (Non-Progressors) and AD (Progressors) groups

\section{Clinical data}

history of vascular disease or vascular risk factors (except smoking)

history of cancer

alcohol comsumption

family history of dementia

identified physical or psychological

for memory impairment

worsening of memory over the previous year, as judged by the informant

presence of emotional changes, as judged by the informant

evidence of loss of functional abilities

presence of behavioral changes, as judged by the informant

presence of symptoms of depression

(Geriatric Depression Scale >6)

abnormal neurologic examination

(including frontal release signs)

frontal release signs alone

\section{$\%$ overall sample}

$\%$ progressors

$\%$ non-progressors

Chi-square $p$ value

53

21

44

43

30

80

26

48

14

58

20

16
60

20

45

46

31

88

31

53

10

55

16

14
0.15

0.77

0.92

0.48

0.87

0.83

0.48

0.32

0.73

0.53

0.60

0.65 
Table 4: Results of logistic regression analysis

\begin{tabular}{lccc}
\hline variable & odds ratio & 95\% confidence interval & $p$ value \\
age at symptom onset & 1.11 & $1.04-1.18$ & 0.002 \\
MMSE & 0.77 & $0.59-1.00$ & 0.055 \\
smoking (packs yrs) & 0.98 & $0.95-1.00$ & 0.13 \\
\hline
\end{tabular}

\section{Discussion}

This study describes a well-characterized cohort of elderly subjects with mild memory impairment meeting current criteria for amnestic MCI as well as CDR 0.5. A wealth of clinical information was derived from a semi-structured interview of both the subject and a close family member, in addition to a detailed physical examination. After consideration of a number of demographic and clinical variables, only older age at symptom onset was associated with progression to probable AD in this group. Basically, there were no clear clues on history or physical exam of an (amnestic) MCI individual that could clearly have predicted whether the individual had a high or low risk of progressing to dementia.

Older age is a known risk factor for $\mathrm{AD},{ }^{30}$ and has been associated with development of dementia in subjects with 'questionable dementia' at presentation. ${ }^{15,24}$ The subjects in our group who noted memory difficulties at an older age were more likely to develop dementia, with an odds ratio of 1.1 for each added year at time of presentation. There was, however, considerable overlap in age at onset of symptoms between the two groups. This finding does suggest that memory complaints that begin at a younger age may have a more benign prognosis in people presenting with mild memory impairment.

Some population-based studies have found the incidence of Alzheimer's disease to be higher among women, ${ }^{30,39-41}$ while others have not, ${ }^{42,44,46}$ Devenand et al, in a smaller and slightly differently defined cohort of elderly subjects with mild memory impairment found no association between female sex and the development of dementia. ${ }^{15} \mathrm{We}$ confirm this finding in our cohort.

The MMSE is a widely used tool for assessment of mental status in the elderly. The subjects reported here scored in a narrow range (23-30) consistent with their mild impairment clinically and on more detailed neuropsychological testing. On average, MMSE scores were slightly but significantly lower at presentation in those who progressed to dementia. However, the MMSE score was not found to contribute significantly in the multivariate predictive model.

There is conflicting data about the role of smoking in the development of AD. In a number of population-based studies, it has been inversely associated with development of dementia, suggesting a possible protective effect. ${ }^{87,88}$ Other studies have found the opposite..$^{30,60} \mathrm{~A}$ variety of explanations have been advanced to explain either possibility, ranging from selection of a 'hardy' subgroup of elderly smokers, to a protective role for central nicotinic receptors. ${ }^{89}$ In the present study, the number of subjects who had a history of ever having smoked was similar in both subgroups (50\% overall). There was more divergence between the groups with regard to cumulative smoking history (pack-years), with those in the stable subgroup smoking more on average. This difference did not reach statistical significance.

It has been suggested that caregiver assessment of memory impairment is more meaningful than the subjects' own assessments, ${ }^{51}$ and that caregivers can accurately detect subtle impairment before measurable neuropsychological deficits are evident. ${ }^{8,53}$ Caregiver report of memory decline with an impact on function over the previous 12 months has previously been found to predict the development of dementia. ${ }^{67}$ This study fails to substantiate this claim. Neither subjective memory complaints nor caregiver report of decline was useful in distinguishing Progressors from Non-Progressors.

There are few reliable signs on neurological exam which indicate the presence of dementia beyond the mental status abnormalities. Frontal release signs, impaired gait, and increased rigidity have been reported to accompany the disease and modify its clinical expression. ${ }^{31,61,62}$ The finding of extrapyramidal signs in community-residing individuals has been found to substantially increase the risk of subsequent dementia. ${ }^{63,90}$ Furthermore, there are suggestions that if cognitive impairment of any degree is present, the additional presence of mild extrapyramidal signs strongly predicts eventual development of dementia; Richards et al found that $45 \%$ of such people had developed dementia at the end of two years' follow-up. ${ }^{63}$ Extrapyramidal signs were found in only 1 of 90 subjects in our cohort. Eighty percent of the cohort had a normal neurological exam, with no difference between subgroups. Only $16 \%$ of the subjects had frontal release signs, and again, there was no difference between the subgroups. There were thus no predictive differences in physical findings in the two subgroups.

The finding that $56 \%$ of people with MCI developed dementia over a mean follow-up of six years highlights the importance of distinguishing those with stable memory deficits, 
and those at an early stage of dementia. Making this distinction will be important both for counseling patients presenting with these complaints, and for planning treatment. Despite detailed clinical assessments, only age at symptom onset served to help predict the development of dementia in people with mild memory impairment in this study.

We wish to acknowledge two important caveats in this study. First, newer clinical risk factors were not included in the assessment. In the past few years it has become evident that degree of cognitive activity, ${ }^{91}$ physical activity ${ }^{92}$ and even social activity ${ }^{93}$ have a protective effect. There is a beneficial effect of social network, physical leisure, and non-physical activity on cognition which might have a protective effect against progression to dementia ${ }^{94}$ but these factors were not clearly assessed in our people. Other new risk factors include diet and recent weight loss and this was also not assessed properly. ${ }^{95,96}$ There is also recent evidence that loneliness and chronic distress increase the risk of $\mathrm{AD},{ }^{97-99}$ but these psychological factors were not assessed in this study. Finally, we did not assess formally for the use of particular medications with anticholinergic side effects, which have been found in $9 \%$ of MCI subjects. ${ }^{100} \mathrm{We}$ consider it unlikely that any of these would have provided definitive prognostication information however. The second caveat is the question of power. It is possible that this study was underpowered to demonstrate significant clinical features (such as behavioural changes) that were present in only a small subset of the cohort.

Our data strongly suggest, however, that ancillary data, whether from objective neuropsychological assessment, imaging studies, CSF or blood biomarkers, genetic analyses or a combination thereof will be necessary in the future to allow a more precise prognostication of individuals with MCI.

\section{ACKNOWLEDGMENTS}

This work was supported by the Fonds de la Recherche en Santé du Québec (FRSQ), the Alzheimer's Society of Canada, and the CIHR (Canadian Institutes of Health Research). We thank the clinical staff of the Jewish General Hospital Memory Clinic for their cooperation, Shelley Solomon for outstanding administrative assistance, and Victor Whitehead for technical and statistical analyses.

\section{REFERENCES}

1. Chertkow H. Mild cognitive impairment. Curr Opin Neurol. 2002; 15(4):401-7.

2. Chertkow H, Nasreddine Z, Joanette Y, Drolet V, Kirk J, Massoud $\mathrm{F}$, et al. Mild cognitive impairment and cognitive impairment, no dementia: part A, concept and diagnosis. Alzheimers Dement. 2007;3(4):266-82.

3. The ICD-10 Classification of Mental and Behavioral Disorders: Clinical Descriptions and Diagnostic Guidelines. Geneva, Switzerland: World Health Organization; 1992.

4. Petersen RC, Smith GE, Waring SC, Ivnik RJ, Tangalos EG, Kokmen E. Mild cognitive impairment: clinical characterization and outcome. Arch Neurol. 1999;56(3):303-8.

5. Petersen RC, Stevens JC, Ganguli M, Tangalos EG, Cummings JL, DeKosky ST. Practice parameter: early detection of dementia: mild cognitive impairment (an evidence-based review). Report of the Quality Standards Subcommittee of the American Academy of Neurology. Neurology. 2001;56(9):1133-42.
6. Winblad B, Palmer K, Kivipelto M, Jelic V, Fratiglioni L, Wahlund LO, et al. Mild cognitive impairment--beyond controversies, towards a consensus: report of the International Working Group on Mild Cognitive Impairment. J Intern Med. 2004;256(3): 240-6.

7. Berg L. Clinical dementia rating (CDR). Psychopharmacol Bull. 1988; 24(4):637-9.

8. Morris JC, McKeel DW, Jr., Storandt M, Rubin EH, Price JL, Grant EA, et al. Very mild Alzheimer's disease: informant-based clinical, psychometric, and pathologic distinction from normal aging. Neurology. 1991;41(4):469-78.

9. Petersen RC. Mild cognitive impairment or questionable dementia? Arch Neurol. 2000;57(5):643-4.

10. Morris JC, Storandt M, Miller JP, McKeel DW, Price JL, Rubin EH, et al. Mild cognitive impairment represents early-stage Alzheimer disease. Arch Neurol. 2001;58(3):397-405.

11. Levy R. Aging-associated cognitive decline. International Geriatrics. 1994;6(1):63-7.

12. Patterson C, Feightner J, Garcia A, MacKnight C. General risk factors for dementia: a systematic evidence review. Alzheimers Dement. 2007;3(4):341-7.

13. Alexopoulos P, Grimmer T, Perneczky R, Domes G, Kurz A. Do all patients with mild cognitive impairment progress to dementia? J Am Geriatr Soc. 2006;54(6):1008-10.

14. Eckman CB, Eckman EA. An update on the amyloid hypothesis. Neurol Clin. 2007;25(3):669-82.

15. Devanand DP, Folz M, Gorlyn M, Moeller JR, Stern Y. Questionable dementia: clinical course and predictors of outcome. J Am Geriatr Soc. 1997;45(3):321-8.

16. Flicker C, Ferris SH, Reisberg B. Mild cognitive impairment in the elderly: predictors of dementia. Neurology. 1991;41(7): 1006-9.

17. Bowen J, Teri L, Kukull W, McCormick W, McCurry SM, Larson EB. Progression to dementia in patients with isolated memory loss. Lancet. 1997;349:763-5.

18. Bennett DA, Schneider JA, Bienias JL, Evans DA, Wilson RS. Mild cognitive impairment is related to Alzheimer disease pathology and cerebral infarctions. Neurology. 2005;64(5):834-41.

19. Petersen RC, Smith, GE, Tangalos, EG, Kokmen, E, Ivnik, RJ. Longitudinal outcome of patients with a mild cognitive impairment. Ann Neurol. 1993;34:294-5.

20. Grundman M, Thal L. Clinical trials to prevent Alzheimer's disease in a population at-risk, in Alzheimer disease: In: Molecular Biology to Therapy, Becker R, Giacobini E, Editors. Boston: Birkhauser; 1996. p. 375-9.

21. Thal LJ. Potential prevention strategies for Alzheimer disease [see comments]. Alzheimer Dis Assoc Disord. 1996;10(Suppl 1):6-8.

22. Dawe B, Procter A. Concepts of mild memory impairment in the elderly and their relationship to dementia - a review. Int J Geriatr Psychiatry. 1992;7:473-9.

23. Ritchie K, Leibovici D, Ledesert B, Touchon J. A typology of subclinical senescent cognitive disorder. B J Psychiatry. 1996; 168(4):470-6.

24. Visser PJ, Kester A, Jolles J, Verhey F. Ten-year risk of dementia in subjects with mild cognitive impairment. Neurology. 2006; 67(7):1201-7.

25. Chertkow H, Bergman H, LeBlanc A, McKelvey R, Chong G, Whitehead V. Amnestic Mild Cognitive Impairment, Natural history and progression to dementia in a memory clinic. Neurology. 2006; (submitted).

26. Chertkow H. Five year follow-up of Mild Cognitive Impairment predictors of progression. The 8th International Conference on Alzheimer's Disease and Related Disorders. Stockholm; 2002.

27. Griffith HR, Netson KL, Harrell LE, Zamrini EY, Brockington JC, and Marson DC. Amnestic mild cognitive impairment: diagnostic outcomes and clinical prediction over a two-year time period. J Int Neuropsychol Soc. 2006;12(2):166-75.

28. Visser PJ, Verhey F, Scheltens P, Cruts M, Ponds RW, Van Broeckhoven C, et al. Diagnostic accuracy of the Preclinical AD Scale (PAS) in cognitively mildly impaired subjects. J Neurol. 2001;249:312-19. 
29. Fleisher AS, Sowell BB, Taylor C, Gamst AC, Petersen RC, Thal LJ. Clinical predictors of progression to Alzheimer disease in amnestic mild cognitive impairment. Neurology. 2007.

30. Lauren L, Andersen K, Dewey M, Latenneur L, Ott A, Amaducci L, et al. Rates and risk factors for dementia and Alzheimer's disease: results from EURODEM pooled analyses. 1999;52: 78-84.

31. Mayeux R, Stern Y, and Spanton S. Heterogeneity in dementia of the Alzheimer's type: evidence of subgroups. Neurology. 1985;35(4):453-61.

32. Mortimer JA, French LR, Hutton JT, Schuman LM. Head injury as a risk factor for Alzheimer's disease. Neurology. 1985;35(2): 264-7.

33. Borenstein AR, Copenhaver CI, Mortimer JA. Early-life risk factors for Alzheimer disease. Alzheimer Dis Assoc Disord. 2006; 20(1):63-72.

34. Jorm A, Duijn Cv, Chandra V, and al. e. Psychiatric history and related exposures as risk factors for Alzheimer's disease: a collaborative re-analysis of case-control studies. EURODEM Risk Factors Research Group. Int J Epidemiol. 1991;20 Suppl 2:S43-7

35. Green RC, Cupples LA, Kurz A, Auerbach S, Go R, Sadovnick D, et al. Depression as a risk factor for Alzheimer disease: the MIRAGE Study. Arch Neurol. 2003;60(5):753-9.

36. Mortimer JA, Graves AB. Education and other socioeconomic determinants of dementia and Alzheimer's disease. Neurology. 1993;43 Suppl 4:S39-S44.

37. Small GW, La Rue A, Komo S, Kaplan A, Mandelkern MA. Predictors of cognitive change in middle-aged and older adults with memory loss. Am J Psychiatry. 1995;152(12):1757-64.

38. Kivipelto M, Ngandu T, Laatikainen T, Winblad B, Soininen H, Tuomilehto J. Risk score for the prediction of dementia risk in 20 years among middle aged people: a longitudinal, populationbased study. Lancet Neurol. 2006;5(9):735-41.

39. Brayne C, Gill C, Huppert FA, Barkley C, Gehlhaar E, Girling DM, et al. Incidence of clinically diagnosed subtypes of dementia in an elderly population: Cambridge Project for later life. Br J Psychiatry. 1995; 167:255-62

40. Fratiglioni L, Viitanen M, von Strauss E, Tontodonati V, Herlitz A, Winblad B. Very old women at highest risk of dementia and probable Alzheimer's disease in a general population: the Framingham Study. Neurology. 1997;48:132-8.

41. Yoshitake T, Kiyohara Y, Kato I, Ohmura T, Iwamoto H, Nakayama $\mathrm{K}$, et al. Incidence and risk factors of vascular dementia and Alzheimer's disease in a defined elderly Japanese population: the Hisayama Study. Neurology. 1995; 45:1161-8.

42. Bachman DL, Wolf PA, Linn RT, Knoefel JE, Cobb JL, Belanger $\mathrm{AJ}$, et al. Incidence of dementia and probable Alzheimer's disease in a general population: the Framingham Study. Neurology. 1993;43(3 Pt 1):515-9.

43. Andersen K, Nielsen H, Lolk A, Andersen J, Becker I, KraghSørensen P. Incidence of very mild to severe dementia and Alzheimer's disease in Denmark: the Odense. Neurology. 1999:52:85-90.

44. Paykel E, Brayne C, Huppert F, Gill C, Barkley C, Gehlhaar E, et al. Incidence of dementia in a population older than 75 years in the United Kingdom. Arch Gen Psychiatry. 1994;51:325-32.

45. Barnes LL, Wilson RS, Schneider JA, Bienias JL, Evans DA, Bennett DA. Gender, cognitive decline, and risk of AD in older persons. Neurology. 2003;60(11):1777-81.

46. Kryscio RJ, Schmitt FA, Salazar JC, Mendiondo MS, Markesbery WR. Risk factors for transitions from normal to mild cognitive impairment and dementia. Neurology. 2006;66(6):828-32.

47. Schmand B, Jonker C, Hooijer C, Lindeboom J. Subjective memory complaints may announce dementia. Neurology. 1996;46(1):121-5.

48. Schofield PW, Jacobs D, Marder K, Sano M, Stern Y. The validity of new memory complaints in the elderly. Arch Neurol. 1997;54(6):756-9.

49. Jonker C, Launer LJ, Hooijer C, Lindeboom J. Memory complaints and memory impairment in older individuals. J Am Geriatr Soc. $1996 ; 44(1): 44-9$
50. Barnes LL, Schneider JA, Boyle PA, Bienias JL, Bennett DA. Memory complaints are related to Alzheimer disease pathology in older persons. Neurology. 2006;67(9):1581-5.

51. McGlone J, Gupta S, Humphrey D, Oppenheimer S, Mirsen T, Evans DR. Screening for early dementia using memory complaints from patients and relatives. Arch Neurol. 1990;47(11):1189-93.

52. Galvin JE, Roe CM, Powlishta KK, Coats MA, Muich SJ, Grant E, et al. The AD8: a brief informant interview to detect dementia. Neurology. 2005;65(4):559-64.

53. Galvin JE, Roe CM, Xiong C, Morris JC. Validity and reliability of the AD8 informant interview in dementia. Neurology. 2006;67(11):1942-8

54. Busse A, Bischkopf J, Riedel-Heller SG, Angermeyer MC. Subclassifications for mild cognitive impairment: prevalence and predictive validity. Psychol Med. 2003;33(6):1029-38.

55. Hofman A, de Jong PT, van Duijn CM, Breteler MM. Epidemiology of neurological diseases in elderly people: what did we learn from the Rotterdam Study? Lancet Neurol. 2006;5(6):545-50.

56. De Groot JC, De Leeuw FE, Oudkerk M, Van Gijn J, Hofman A, Jolles $\mathrm{J}$, et al. Periventricular cerebral white matter lesions predict rate of cognitive decline. Ann Neurol. 2002;52(3): 335-41.

57. den Heijer T, Geerlings MI, Hoebeek FE, Hofman A, Koudstaal PJ, Breteler MM. Use of hippocampal and amygdalar volumes on magnetic resonance imaging to predict dementia in cognitively intact elderly people. Arch Gen Psychiatry. 2006;63(1):57-62.

58. van Oijen M, de Jong FJ, Witteman JC, Hofman A, Koudstaal PJ, Breteler MM. Atherosclerosis and risk for dementia. Ann Neurol. 2007;61(5):403-10.

59. van Dijk EJ, Breteler MM, Schmidt R, Berger K, Nilsson LG, Oudkerk $\mathrm{M}$, et al. The association between blood pressure, hypertension, and cerebral white matter lesions: cardiovascular determinants of dementia study. Hypertension. 2004;44(5): 625-30.

60. Almeida OP, Hulse GK, Lawrence D, Flicker L. Smoking as a risk factor for Alzheimer's disease: contrasting evidence from a systematic review of case-control and cohort studies. Addiction. 2002;97(1):15-28.

61. Chui HC, Lyness SA, Sobel E, Schneider LS. Extrapyramidal signs and psychiatric symptoms predict faster cognitive decline in Alzheimer's disease. Arch Neurol. 1994;51(7):676-81.

62. Huff FJ, Boller F, Lucchelli F, Querriera R, Beyer J, Belle S. The neurologic examination in patients with probable Alzheimer's disease. Arch Neurol. 1987;44:929-33.

63. Richards M, Folstein M, Albert M, Miller L, Bylsma F, Lafleche G, et al. Multicenter study of predictors of disease course in Alzheimer disease (the "predictors study"). II. Neurological, psychiatric, and demographic influences on baseline measures of disease severity. Alzheimer Dis Assoc Disord. 1993;7(1):22-32. [published erratum appears in Alzheimer Dis Assoc Disord 1993 Winter;7(4):239]

64. O'Keeffe ST, Kazeem H, Philpott RM, Playfer JR, Gosney M, Lye M. Gait disturbance in Alzheimer's disease: a clinical study. Age Ageing. 1996;25(4):313-6.

65. Ramakers IH, Visser PJ, Aalten P, Boesten JH, Metsemakers JF, Jolles J, et al. Symptoms of preclinical dementia in general practice up to five years before dementia fiagnosis. Dement Geriatr Cogn Disord. 2007;24(4):300-6.

66. Tierney MC, Szalai JP, Snow WG, Fisher RH, Nores A, Nadon G, et al. Prediction of probable Alzheimer's disease in memoryimpaired patients: a prospective longitudinal study. Neurology. 1996;46(3):661-5.

67. Rubin EH, Morris JC, Grant EA, Vendegna T. Very mild senile dementia of the Alzheimer type. I. Clinical assessment. Arch Neurol. 1989;46(4):379-82

68. Galvin JE, Roe CM, Morris JC. Evaluation of cognitive impairment in older adults: combining brief informant and performance measures. Arch Neurol. 2007;64(5):718-24

69. Gauthier S, Reisberg B, Zaudig M, Petersen RC, Ritchie K, Broich K, et al. Mild cognitive impairment. Lancet. 2006;367 (9518): 1262-70. 
70. Petersen RC, R. VN, Ivnik RJ, Tangalos EG, Kokmen E. "Mild cognitive impairment: linical characterization and outcome". Correction. Arch Neurol. 1999;56(6).

71. Portet F, Ousset PJ, Visser PJ, Frisoni GB, Nobili F, Scheltens P, et al. Mild cognitive impairment (MCI) in medical practice: a critical review of the concept and new diagnostic procedure. Report of the MCI Working Group of the European Consortium on Alzheimer's Disease. J Neurol Neurosurg Psychiatry. 2006;77(6):714-8

72. Petersen RC, Smith GE, Waring SC, Ivnik RJ, Tangalos EG, and Kokmen E. Mild cognitive impairment: clinical characterization and outcome. Arch Neurol. 1999;56(3):303-8. [published erratum appears in Arch Neurol 1999 Jun;56(6):760]

73. Petersen RC, Smith GE, Ivnik RJ, Tangalos EG, Schaid DJ, Thibodeau SN, et al. Apolipoprotein E status as a predictor of the development of Alzheimer's disease in memory-impaired individuals. JAMA. 1995;273(16):1274-8. [published erratum appears in JAMA 1995 Aug 16;274(7):538]

74. Petersen RC. Mild cognitive impairment as a diagnostic entity. J Intern Med. 2004;256(3):183-94.

75. Darvesh S, Leach L, Black SE, Kaplan E, Freedman M. The behavioural neurology assessment. Can J Neurol Sci. 2005; 32(2):167-77.

76. McKhann G, Drachman, D, Folstein, M, Katzman, R, Price, D, Stadlan, EM. Clinical diagnosis of Alzheimer's disease: report of the NINCDS-ADRDA work group under the auspices of the Department of Health Services Task Force on Alzheimer's diesase. Neurology. 1984;34:939-44.

77. Hughes C, Berg L, Danziger W, Coben L, Martin R. A new clinical scale for the staging of dementia. B J Psychiatry. 1982;140: 566-72.

78. Babins L, Slater ME, Whitehead V, and Chertkow HM. Can an 18point clock drawing scoring system predict dementia in elderly individuals with mild cognitive impairment? J Clin Exp Neuropsychol. 2007:1-14.

79. Duong A, Whitehead V, Hanratty K, Chertkow H. The nature of lexico-semantic processing deficits in mild cognitive impairment. Neuropsychologia. 2006;44(10):1928-35.

80. Chertkow H. Mild Cognitive Impairment. The Canadian Azheimer's Disease Review. 2002:15-20.

81. Tabert MH, Albert SM, Borukhova-Milov L, Camacho Y, Pelton G, Liu X, et al. Functional deficits in patients with mild cognitive impairment: prediction of AD. Neurology. 2002;58(5):758-64.

82. Hachinski VC, Iliff LD, Zilhka E, duBoulay GHD, McAllister VL, Marshall J, et al. Cerebral blood flow in dementia. Arch Neurol. 1975;32:632-7.

83. Folstein MF, Folstein SE, and McHugh PR. "Mini-mental state": a practical method for grading the cognitive state of patients for the clinician. J Psychiatr Res 1975;12(3):189-98.

84. Yesavage JA. Geriatric Depression Scale. Psychopharmacol Bull. 1988;24(4):709-11.

85. Spreen O and Strauss E, eds. A compendium of neuropsychological tests: Administration norms and commentary. New York: Oxford University Press; 1998. p. 326-40.

86. Wechsler D. Wechsler Memory Scale - Revised. San Antonio: The Psychological Corporation; 1987.

87. Brenner DE, Kukull WA, van Belle G, Bowen JD, McCormick WC, Teri L, et al. Relationship between cigarette smoking and Alzheimer's disease in a population-based case-control study. Neurology. 1993;43(2):293-300.
88. Graves AB, van Duijn CM, Chandra V, Fratiglioni L, Heyman A, Jorm AF, et al. Alcohol and tobacco consumption as risk factors for Alzheimer's disease: a collaborative re-analysis of casecontrol studies. EURODEM Risk Factors Research Group. Int J Epidemiol. 1991;20 Suppl 2:S48-57.

89. Quirion R. Cholinergic markers in Alzheimer disease and the autoregulation of acetylcholine release. J Psychiatry Neurosci. 1993; 18(5):226-34.

90. Louis ED, Schupf N, Manly J, Marder K, Tang MX, Mayeux R. Association between mild parkinsonian signs and mild cognitive impairment in a community. Neurology. 2005;64(7):1157-61.

91. Wilson RS, Scherr PA, Schneider JA, Tang Y, Bennett DA. The relation of cognitive activity to risk of developing Alzheimer's disease. Neurology. 2007;69(20):1911-20.

92. Laurin D, Verreault R, Lindsay J, MacPherson K, Rockwood K. Physical activity and risk of cognitive impairment and dementia in elderly persons. Arch Neurol. 2001;58(3):498-504.

93. Verghese J, Levalley A, Derby C, Kuslansky G, Katz M, Hall C, et al. Leisure activities and the risk of amnestic mild cognitive impairment in the elderly. Neurology. 2006; 66:821-7.

94. Fratiglioni L, Paillard-Borg S, Winblad B. An active and socially integrated lifestyle in late life might protect against dementia. Lancet Neurol. 2004;3(6):343-53.

95. Engelhart MJ, Geerlings MI, Ruitenberg A, Van Swieten JC, Hofman A, Witteman JC, et al. Diet and risk of dementia: Does fat matter? The Rotterdam Study. Neurology. 2002;59(12): 1915-21.

96. Knopman DS, Edland SD, Cha RH, Petersen RC, Rocca WA. Incident dementia in women is preceded by weight loss by at least a decade. Neurology. 2007;69(8):739-46.

97. Wilson RS, Arnold SE, Schneider JA, Li Y, Bennett DA. Chronic distress, age-related neuropathology, and late-life dementia. Psychosom Med. 2007;69(1):47-53.

98. Wilson RS, Krueger KR, Arnold SE, Schneider JA, Kelly JF, Barnes LL, et al. Loneliness and risk of Alzheimer disease. Arch Gen Psychiatry. 2007;64(2):234-40.

99. Wilson RS, Schneider JA, Boyle PA, Arnold SE, Tang Y, Bennett DA. Chronic distress and incidence of mild cognitive impairment. Neurology. 2007;68(24):2085-92.

100. Ancelin ML, Artero S, Portet F, Dupuy AM, Touchon J, Ritchie K. Non-degenerative mild cognitive impairment in elderly people and use of anticholinergic drugs: longitudinal cohort study. BMJ. 2006;332(7539):455-9. 